\title{
An Assessment of Pharmacological Properties of Schinus Essential Oils A Soft Computing Approach
}

\author{
José Neves \\ Algoritmi \\ Universidade do Minho \\ Braga, Portugal \\ jneves@di.uminho.pt \\ Fátima Candeias, Sílvia Arantes \\ Departamento de Química \\ Escola de Ciências e Tecnologia \\ Instituto de Ciências Agrárias e Ambientais Mediterrânicas \\ Universidade de Évora, Évora, Portugal \\ $\{\mathrm{mfbc}, \mathrm{saa}\} @$ uevora.pt \\ M. Rosário Martins \\ Departamento de Química \\ Escola de Ciências e Tecnologia \\ Laboratório HERCULES \\ Universidade de Évora, Évora, Portugal \\ mrm@uevora.pt \\ Ana Piteira \\ Departamento de Química \\ Escola de Ciências e Tecnologia \\ Universidade de Évora, Évora, Portugal \\ anaisabelanaisabel14@hotmail.com \\ Henrique Vicente \\ Departamento de Química \\ Escola de Ciências e Tecnologia \\ Universidade de Évora, Évora, Portugal \\ Algoritmi, Universidade do Minho \\ hvicente@uevora.pt
}

\section{KEYWORDS}

Schinus spp., Essential Oils, Logic Programming, Case Base Reasoning, Knowledge Representation and Reasoning, Similarity Analysis.

\begin{abstract}
Plants of genus Schinus are native South America and introduced in Mediterranean countries, a long time ago. Some Schinus species have been used in folk medicine, and Essential Oils of Schinus spp. (EOs) have been reported as having antimicrobial, anti-tumoural and anti-inflammatory properties. Such assets are related with the EOs chemical composition that depends largely on the species, the geographic and climatic region, and on the part of the plants used. Considering the difficulty to infer the pharmacological properties of EOs of Schinus species without a hard experimental setting, this work will focus on the development of an Artificial Intelligence grounded Decision Support System to predict pharmacological properties of Schinus EOs. The computational framework was built on top of a Logic Programming Case Base approach to knowledge representation and reasoning, which caters to the handling of incomplete, unknown, or even selfcontradictory information. New clustering methods centered on an analysis of attribute's similarities were used to distinguish and aggregate historical data according to the context under which it was added to the Case Base, therefore enhancing the prediction process.
\end{abstract}

